\title{
Karakteristik Upwelling pada Periode Indian Ocean Dipole (IOD) Positif di Perairan Selatan Jawa Barat
}

\author{
Dini Oktaviani*, Gentur Handoyo, Muhammad Helmi, Kunarso dan Anindya Wirasatriya \\ Departemen Oseanografi, Fakultas Perikanan dan Ilmu Kelautan, Universitas Diponegoro \\ Jl. Prof. H. Sudarto, SH, Tembalang Semarang. 50275 Telp/fax (024)7474698 \\ Email: *dinioktaviani750@gmail.com
}

\begin{abstract}
Abstrak
Indian Ocean Dipole (IOD) merupakan suatu pola variabilitas di Samudera Hindia dengan perubahan Suhu Permukaan Laut (SPL) yang lebih rendah daripada biasanya. Secara umum perubahan variabilitas suhu permukaan laut dan persebaran klorofil-a di laut sangat dipengaruhi oleh adanya fenomena Indian Ocean Dipole (IOD). Adanya fenomena IOD ini berpengaruh pada terjadinya upwelling pada perairan selatan Jawa Barat.Tujuan dari penelitian ini adalah untuk mengetahui karakteristik dan hubungan Indian Ocean Dipole (IOD) dengan upwelling di perairan selatan Provinsi Jawa Barat. Metode yang digunakan yaitu metode kuantitatif, metode ilmiah yang dianalisis menggunakan kaidah-kaidah ilmiah yang empiris, rasional dan sistematis. Penelitian ini dilakukan menggunakan data satelit tahun 2008 sampai dengan 2017. Materi yang digunakan dalam penelitian ini adalah data Suhu Permukaan Laut (SPL) dan klorofil-a hasil perekaman satelit Aqua MODIS, data Dipole Mode Index (DMI). Data dari satelit diolah menggunakan SeaDas kemudian menggunakan software ArcGIS. Setelah data didapatkan kemudian diolah menggunakan Microsoft Excel. Hasil penelitian menunjukkan bahwa variabilitas IOD mempengaruhi karakteristik upwelling yang terjadi di perairan selatan Jawa Barat. Ketika nilai DMI meningkat maka upwelling menguat yang ditunjukkan indikator SPL menurun dan klorofil-a meningkat. Sebaliknya ketika DMI menurun maka upwelling akan menurun yang ditunjukkan indikator SPL meningkat dan klorofil-a menurun. Upwelling dengan katagori lemah sudah mulai terjadi bulan Mei. Upwelling medium terjadi bulan Juni-Juli dan upwelling kuat umunya terjadi pada bulan Agustus-September.Bulan Oktober-November umumnya upwelling melemah lagi.
\end{abstract}

Kata Kunci : SPL, Klorofil-a, Upwelling, IOD

\begin{abstract}
Indian Ocean Dipole (IOD) is a pattern of variability in the Indian Ocean with changes in Sea Surface Temperature (SST) that are lower than usual. In general, changes in the variability of sea surface temperature and the distribution of chlorophyll-a in the sea are strongly influenced by the Indian Ocean Dipole (IOD) phenomenon. The existence of this IOD phenomenon affects the occurrence of upwelling in the southern waters of West Java. The purpose of this study is to determine the characteristics and relationship of Indian Ocean Dipole (IOD) with upwelling in the southern waters of West Java Province. The method used is a quantitative method, a scientific method analyzed using empirical, rational, and systematic scientific principles. This research was conducted from 2008 to 2017 using satellite data. The material used in this research is the SPL and chlorophyll-a data recorded by the Aqua MODIS satellite, the Dipole Mode Index (DMI) data. Data from the satellite is processed using SeaDas then using ArcGIS software. After the data is obtained, it is processed using Microsoft Excel. The results showed that the IOD variability affected the upwelling characteristics that occurred in the southern waters of West Java. When the DMI value increases, the upwelling strengthens, which is indicated by a decreased Sea Surface Temperature (SST) indicator and an increase in chlorophyll-a. On the other hand, when the DMI decreases, the upwelling will decrease, which is indicated by an increased SST indicator and a decrease in chlorophyll-a. Upwelling in the weak category has started to occur in May. Medium upwelling occurs in June-July and strong upwelling generally occurs in August-September. In October-November, upwelling generally weakens again.
\end{abstract}

Keywords: SST, Chlorophyll-a, Upwelling, IOD

https://ejournal2.undip.ac.id/index.php/ijoce

Diterima/Received : 19-08-2021

Disetujui/Accepted : 29-11-2021 


\section{PENDAHULUAN}

Indonesia merupakan negara kepulauan yang terletak diantara 2 Benua yaitu Benua Asia dan Benua Australia, serta terletak antara 2 Samudera yaitu Samudera Pasifik dan Samudera Hindia. Ditinjau dari keadaan tersebut, Indonesia memiliki kondisi arus dan suhu permukaan laut yang dipengaruhi oleh variabilitas paremeter oseanografi pada kedua Samudera, khususnya pada Samudera Hindia. Fenomena oseanografi sering terjadi di Samudera Hindia sering terjadi berbagai seperti fenomena Indian Ocean Dipole (IOD). Fenomena Indian Ocean Dipole (IOD) tersebut berpengaruh terhadap variabilitas oseanografi seperti kondisi arus, suhu permukaan laut, dan persebaran klorofil-a pada perairan Indonesia.

Indian Ocean Dipole (IOD) merupakan suatu fenomena terjadinya anomali suhu permukaan laut hangat/dingin di Samudera Hindia bagian barat yang diikuti terjadinya fenomena suhu muka laut dingin/hangat di Samudra Hindia bagian timurupwelling, wilayah yang kutub (pole) bersuhu dingin terjadi proses upwelling(Saji et al., 1999). Proses upwelling terjadi karena adanya kekosongan massa air di lapisan permukaan, akibat terbawa ke tempat lain oleh arus. Adanya proses upwelling ditandai dengan turunnya suhu permukaan sampai dengan sekitar $2^{\circ} \mathrm{C}$ di daerah tropis dan $>2{ }^{\circ} \mathrm{C}$ pada daerah sub tropis (Dahuri et al., 1996).

Berdasarkan pernyataan tersebut, penelitian perlu dilakukan untuk membahas tentang karakteristik suhu permukaan laut dan fenomena upwelling yang terjadi di wilayah perairan selatan Jawa Barat. Kajian difokuskan pada hubungan antara suhu permukaan laut dan dinamika upwelling pada IOD positif menggunakan data citra satelit Aqua Modis.

\section{MATERI DAN METODE Materi Penelitian}

Materi yang digunakan dalam penelitian ini adalah data Suhu Permukaan Laut dan data Klorofil-a yang diperoleh dari situs resmi NASA yaitu http://oceancolor.gsfc.nasa.gov. Data yang di download merupakan data harian dari tahun 2008 hingga tahun 2017 yang merupakan hasil perekaman dari citra satelit Aqua MODIS. Data tersebut kemudian dikomposit menjadi data bulanan menggunakan Seadas. Nilai Dipole Mode Index (DMI) yang digunakan untuk mengetahui fenomena Indian Ocean Dipole (IOD) diperoleh dari Agency For-Marine Earth Science And Technology (JAMSTEC) melalui situs www.jamstec.go.jp/e/database/index.html dari tahun 2008-2017.

\section{Metode Penelitian}

Metode penelitian ini menggunakan metode kuantitatif, yaitu metode ilmiah/scientific dengan karakteristik konkret/empiris, obyektif, terukur, rasional, dan sistematis. Metode ini disebut kuantitatif karena data penelitian yang digunakan berupa angka-angka dan analisis menggunakan statistik (Sugiyono, 2009). Data empirik yang digunakan meliputi data SPL, Klorofil-a dan data DMI yang erupakan indek IOD.

\section{Waktu dan Lokasi}

Penelitian ini dilakukan pada bulan Juli 2020-Januari 2021 dengan menggunakan data tahun 2008 sampai dengan 2017 di perairan selatan Jawa Barat pada kordinat 105,8 $8^{\circ} \mathrm{BT}$; 7,4 $4^{\circ} \mathrm{SS}$ sampai $106,79^{\circ} \mathrm{BT} ; 8,56^{\circ} \mathrm{LS}$. 


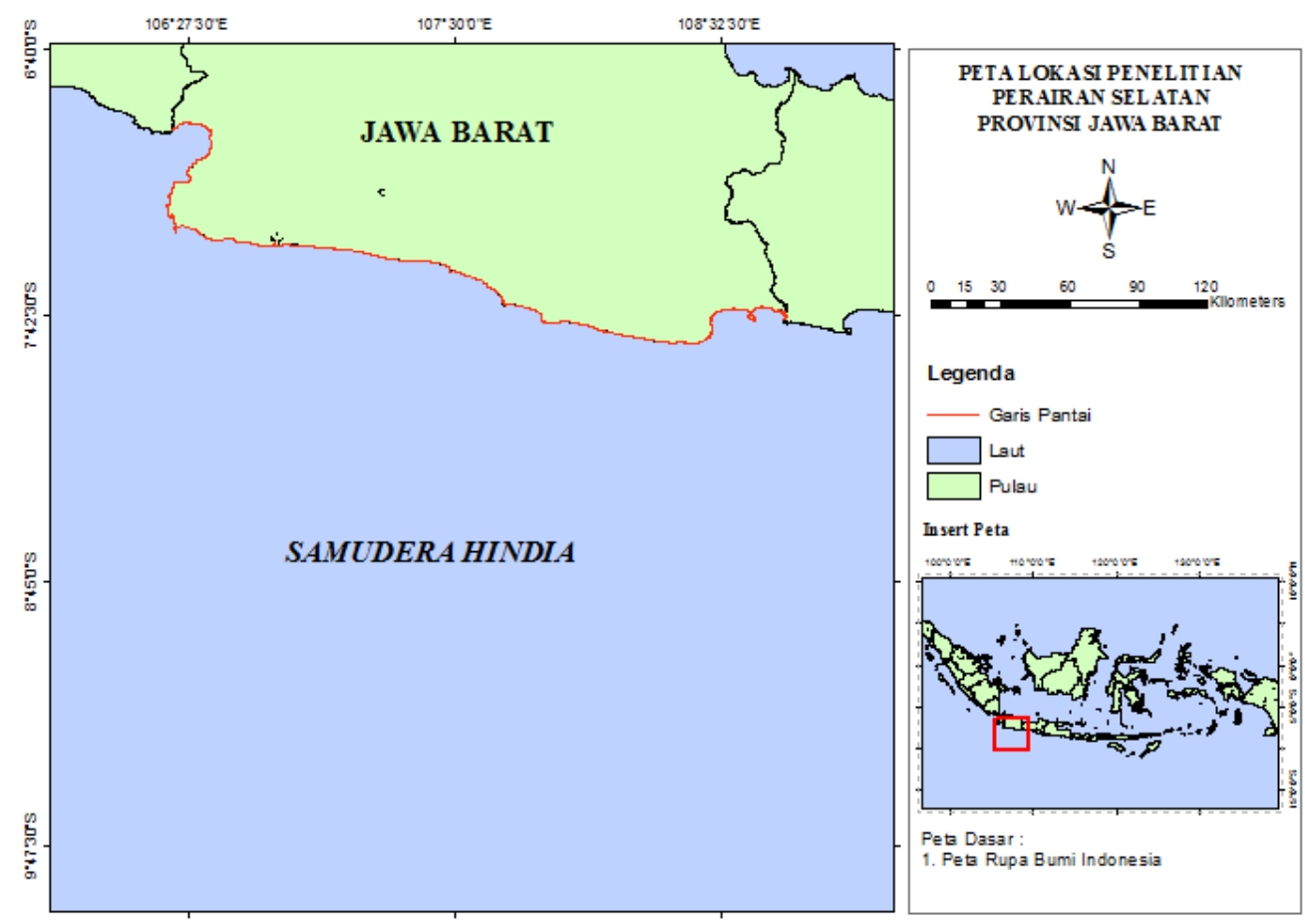

Gambar 1. Peta Lokasi Penelitian

\section{Pengolahan dan Analisis Data}

\section{Pengolahan Data}

Data Suhu Permukaan Laut dan Klorofil-a setelah diunduh, kemudian diolah dengan software SeaDAS, pada area sesuai dengan lokasi penelitian. Data txt citra hasil pengolahan SeaDAS kemudian diolah untuk mapping SPL dan klorofil-a menggunakan software ArcGIS. Ekstrak data SPL dan klorofila bulanan tahun 2008-2017 yang telah dibut rerata klimatologisnya selanjutnya diolah untuk membuat grafis dengan parameter lain.

\section{Analisis Data}

Data citra Suhu Permukaan Laut (SPL) dan Klorofil-a ditampilkan secara spasial untuk mengidentifikasi ada tidaknya upwelling. Indikator upwelling dapat ditinjau berdasarkan sebaran suhu permukaan laut dan klorofil-a, dengan nilai karakteristik SPL $\leq 26^{\circ} \mathrm{C}$, sedangkan untuk nilai klorofil-a yaitu klorofil-a $>0.23 \mathrm{mg} / \mathrm{m}^{3}$. Dipole Mode Indeks (DMI) yang digunakan untuk mengetahui fase dari Indian Ocean Dipole (IOD) berupa indeks bulanan yag didapat dari JAMSTEC.

\section{HASIL DAN PEMBAHASAN}

\section{Hubungan Suhu Perukaan Laut dan Klorofil}

Berdasarkan hasil pengolahan data citra suhu permukaan laut dan klorofil-a (Gambar 2) ditemukan bahwa terjadi kondisi nilai SPL rendah dan nilai klorofil-a tinggi pada saat Musim Timur yang mengindikasikan terjadinya upwelling pada musim timur (Juni, Juli, Agustus) dan peralihan 2 (September, Oktober, November). 


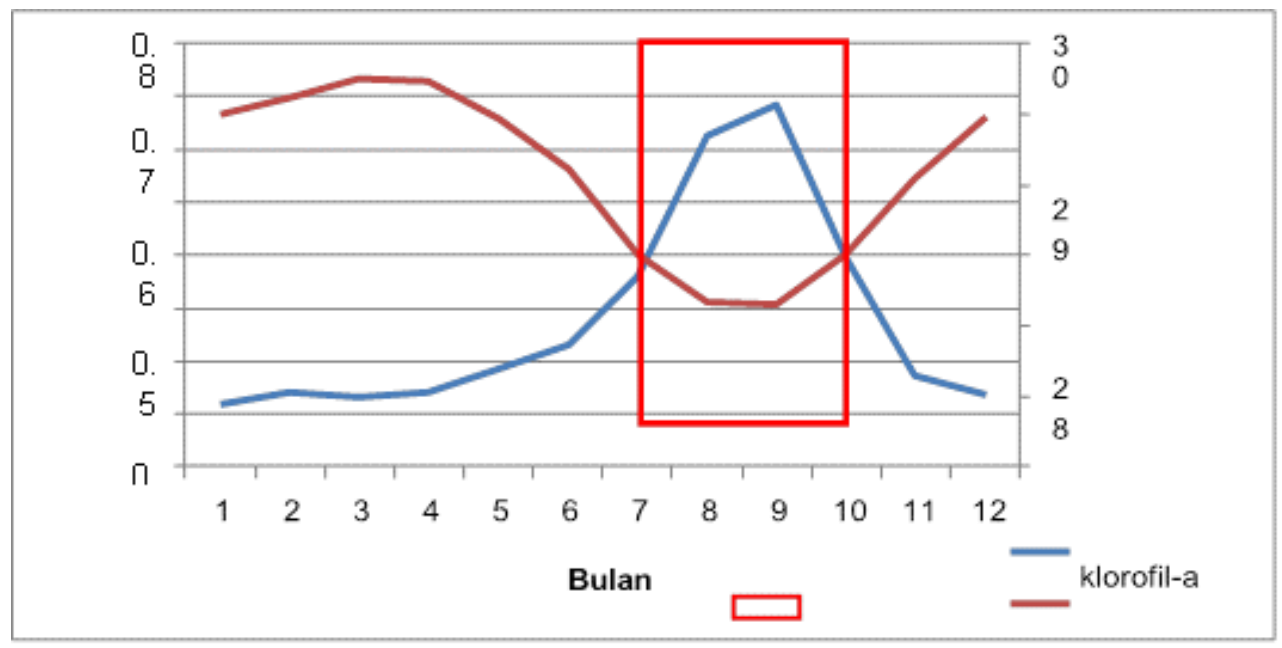

Gambar 2. Hubungan SPL dan klorofil-a di Selatan Jawa Barat

Rendahnya suhu permukaan laut dan tingginya nilai klorofil-a pada Musim Timur-Peralihan Peralihan 2 di perairan selatan Jawa Barat, diduga terjadi karena adanya proses upwelling. Proses upwelling terjadi karena adanya angin yang bertiup secara kontinyu hampir sejajar garis pantai dari arah tenggara ke arah Barat Daya. Angin tersebut yang membangkitkan upwelling di sepanjang selatan Jawa termasuk di wilayah kajian yaitu perairan Selatan Jawa Barat. Hal ini dijelaskan dalam bebrapa paper terdahulu juga yang ditulis oleh Kunarso et al (2005); Susanto and Marra (2005); Wirasatria, at al (2020); Wirasatriya et al (2021). Puncak dari upwelling yang terjadi di perairan selatan Jawa Barat terjadi pada bulan September yang ditandai dengan nilai indkator SPL yang rendah dan klorofil-a yang tinggi (Gambar 3 dan 4).

Fenomena menarik yang ditemukan berdasarkan Gambar 3, 4 dan 5,6,7 yaitu adanya varibilitas upwelling yang terjadi selama bulan September dari tahun 2008 hingga 2017. Hal ini tampak dari indikator SPL dalam Gambar 3, indikator klorofil-a dalam Gambar 4, dan hasil overlay SPL dan klorofil-a dalam Gambar 5. Variabiltas upwelling ini tampak terkait dengan IOD (Gambar 6). Ketika DMI nilainya tinggi sebagaimana kasus tahun 2011, 2012 dan 2015. Menunjukkan nilai SPL di perairan selatan Jawa Barat sangat rendah dan klorofil-a sangat tinggi dan upwelling menguat intensitasnya dan meluas distribusi spasialnya (Gambar 5). Sebaliknya ketika IOD nilainya semakin kecil maka SPL nilainya semakin besar, konsentrasi klorofil-a mengecil, intensitas upwelling menurun dan luasan distribusi spasial menyempit (Gambar 5). Kondisi ini bisa terjadi diduga terkait dengan variabilitas angin sebagai pembangkit yang akan mengali variabilitas dengan adanya variabilitas nilai IOD. Semakin besar nilai DMI (indikator IOD) maka angin tenggara yang bertiup di atas perairan selatan Jawa Barat akan semakin menguat, angin yang sejajar garis pantai ini akan membangkitkan Ekman transport yang arahnya ke Selatan atau Barat Daya, kekosongan masa air dipantai diisi oleh massa air dari lapisan di bawahnya, maka terjadilah upwelling yang kuat ketika IOD bernilai besar. Hal tersebut telah dijelaskan oleh Saji et al., (1998), Kunarso et al., (2005), yang menyatakan bahwa IOD berpengaruh terhadap angin dan variabiltas upwelling di Samudra Hindia bagian timur termasuk perairan di Selatan Jawa Barat. 

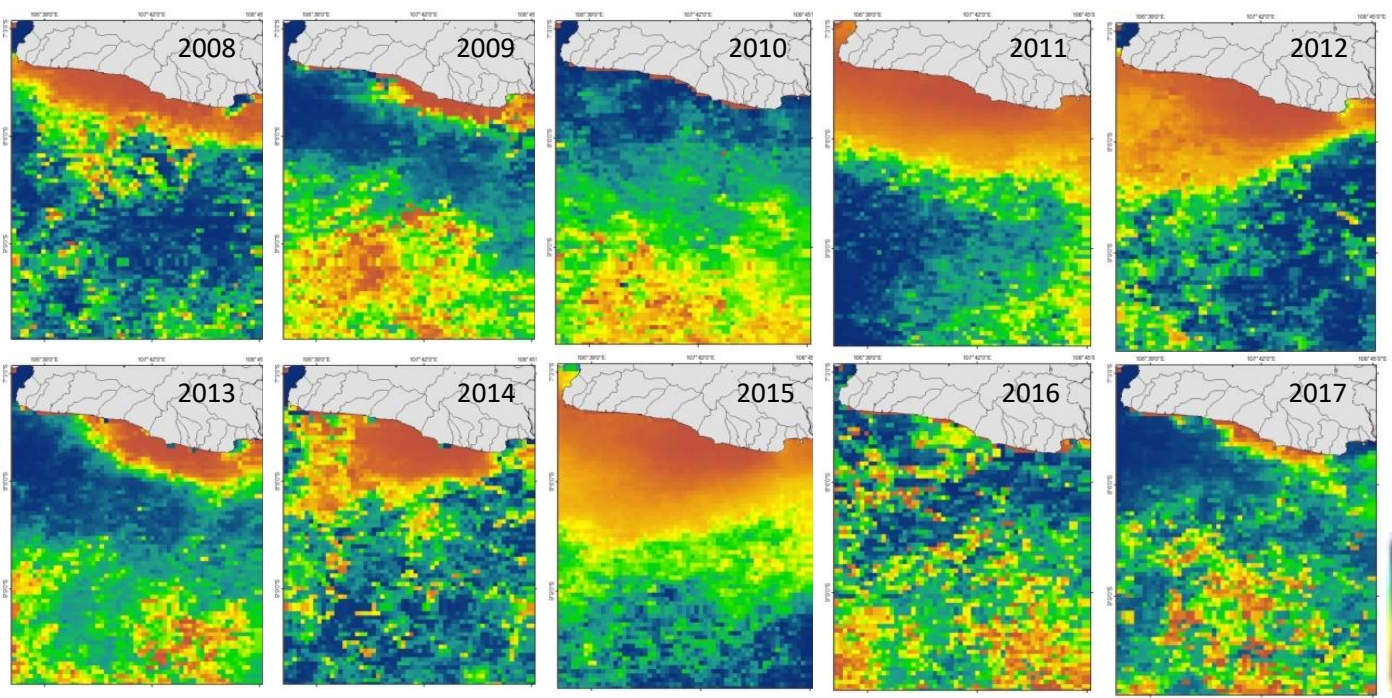

$\left({ }^{\circ} \mathrm{C}\right)$

30

27.5

25

Gambar 3. Rerata Suhu Permukaan Laut bulan September 2008-2017
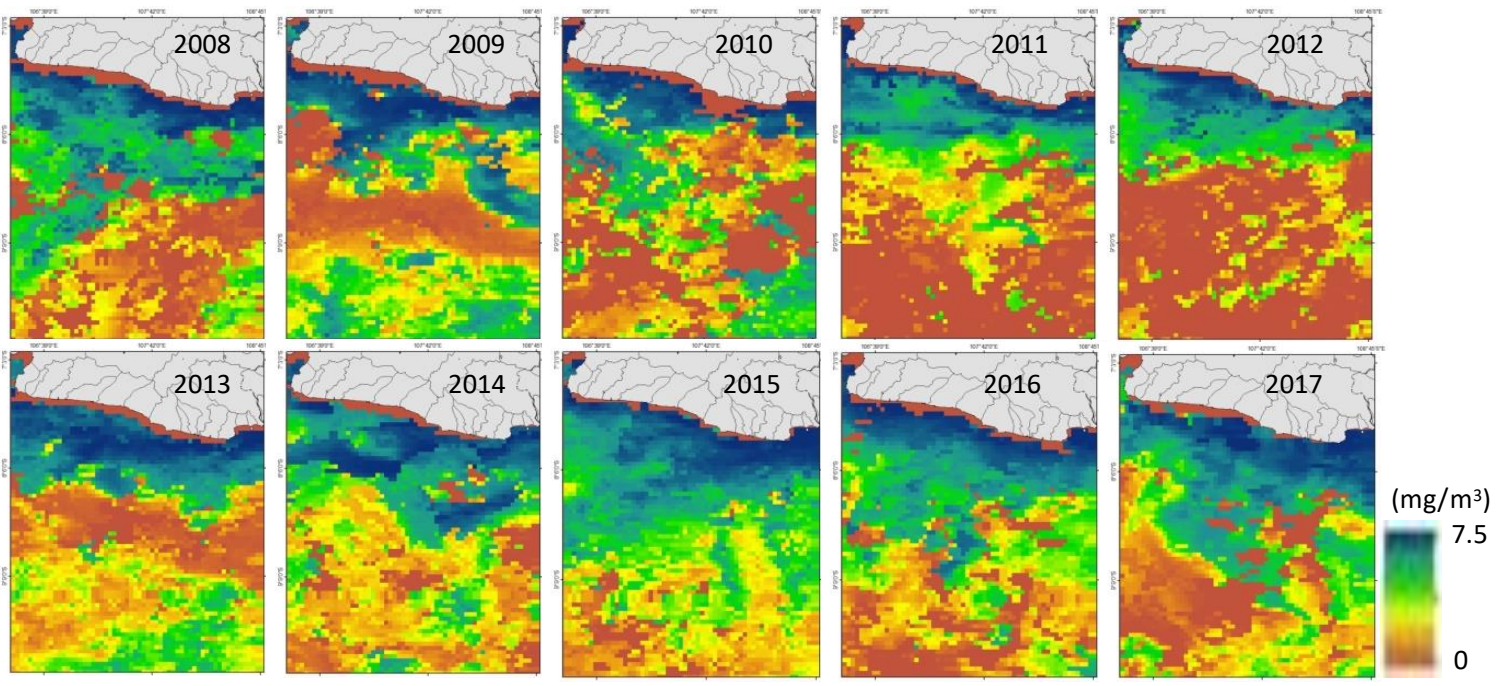

Gambar 4. Rerata Klorofil-a bulan September 2008-2017 


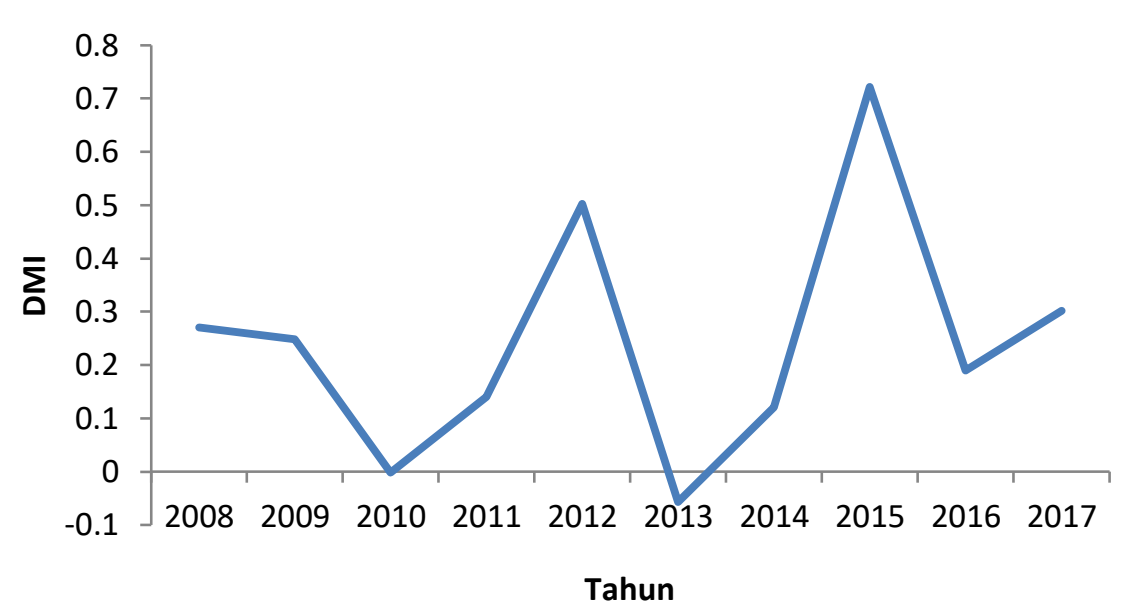

Gambar 5. Nilai DMI Tahun 2008-2017
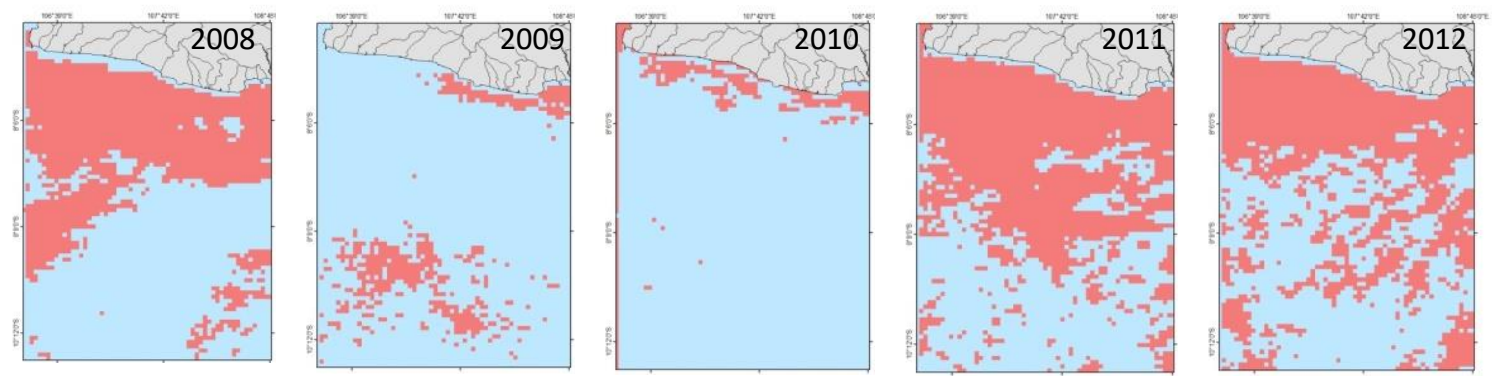

Gambar 6. Upwelling bulan September 2008-2012
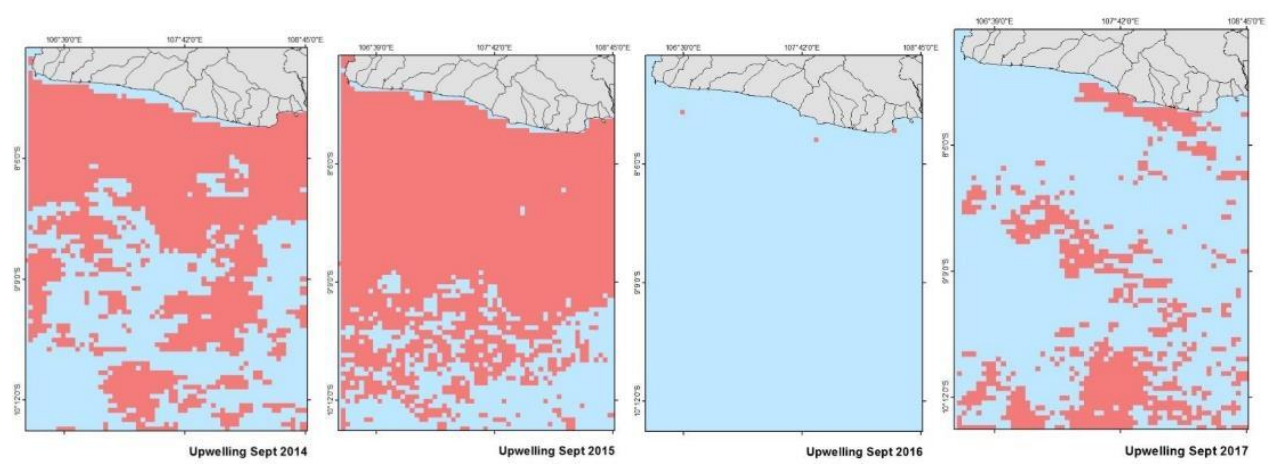

Gambar 7. Upwelling pada bulan September Tahun 2014-2017

\section{Karakteristik Upwelling pada Indian Ocean Dipole (IOD) Positif}

Proses upwelling terjadi karena adanya kekosongan massa air pada lapisan permukaan akibat transport Ekman menjauhi garis pantai atau adanya divergensi arus laut. Upwelling dapat dianalisis berdasarkan indikator SPL dan klorofil-a yaitu ditandai dengan nilai SPL yang rendah dan kandungan klorofil-a yang tinggi dari sekitarnya. Berdasarkan analisis Gambar 3, 4 dan 7 menunjukkan adanya varibilitas upwelling yang terjadi dari tahun 2008 sampai dengan tahun 2017. Berdasarkan data tersebut 
menunjukkan pada bulan Mei sudah menunjukkan adanya upwelling dengan karakteristik indikator SPL lebih dari $28,93^{\circ} \mathrm{C}$, sedangkan konsetrasi klorofil-a kurang dari $0,23 \mathrm{mg} / \mathrm{m}^{3}$. Karakteristik tersebut sesuai dengan hasil riset Kunarso et al (2020) Upwelling medium terjadi pada bulan Juni dan Juli dengan konsentrasi klorofil-a diantara $0,23 \mathrm{mg} / \mathrm{m}^{3}$ dan $0,414 \mathrm{mg} / \mathrm{m}^{3}$, sedangkan untuk suhu permukaan lautnya berada pada kisaran $27,96^{\circ} \mathrm{C}$ sampai dengan suhu $28,937^{\circ} \mathrm{C}$. Bulan Agustus dan September terjadi upwelling kuat dengan nilai SPL pada kisaran $26,996^{\circ} \mathrm{C}$ sampai dengan $27,96^{\circ} \mathrm{C}$, kosentrasi klorofil-a pada bulan tersebut berkisar $0,414 \mathrm{mg} / \mathrm{m}^{3}-0,597 \mathrm{mg} / \mathrm{m}^{3}$. Upwelling di perairan selatan Jawa Barat merupakan fenomena yang terjadi berurutan, berevolusi dari perairan Selatan Jawa Timur ke barat. Adanya variabilitas DMI menunjukkan pengaruh yang nyata merubah indikator upwelling yang berupa SPL dan klorofil-a di perairan Selatan Jawa Barat. Ketika DMI nilainya semakin besar maka SPL menjadi semakin dingin dan konsentrasi klorofil-a meningkat, sebaliknya ketika DMI mengecil, maka SPL semakin tinggi dan klorofil-a menurun.

\section{KESIMPULAN}

Variabilitas IOD nyata mempengaruhi karakteristik upwelling yang terjadi di perairan selatan Jawa Barat. Ketika nilai DMI meningkat maka upwelling menguat yang ditunjukkan indikator SPL menurun dan klorofil-a meningkat. Sebaliknya ketika DMI menurun maka upwelling akan menurun yang ditunjukkan indikator SPL meningkat dan klorofil-a menurun. Upwelling umumnya terjadi dari bulan Mei hingga November, dengan karakteristik lemah umumnya terjadi mulai bulan Mei. Upwelling medium umumnya terjadi pada bulan Juni-Juli dan upwelling kuat umunya terjadi pada bulan AgustusSeptember.Bulan Oktober-November umumnya upwelling melemah lagi.

\section{DAFTAR PUSTAKA}

Anindya Wirasatriya, R. Dwi Susanto, Kunarso Kunarso, Abd. Rasyid Jalil, Fatwa Ramdani \& Ardiansyah Desmont Puryajati. 2021. Northwest Monsoon Upwelling within the Indonesian Seas. International Journal of Remote Sensing, Vol. 42(14) : 5437-5458.

Dahuri, R, J. Rais, S.p Ginting dan M. J. Sitepu. 1996. Pengelolaan Sumberdaya Wilayah Pesisir dan Lautan Secara Terpadu. PT. Pradnya Paramita, Jakarta, 229 hlm.

Kunarso, N.S. Ningsih, A. Supangat. 2005. Karakteristik Upwelling di Sepanjang Perairan NTT hingga Barat Sumatera. Jurnal Ilmu Kelautan, 10 (1).

Hadi, S., Ningsih, N. S., Baskoro, M. S., Wirasatriya, A., \& Kuswardani, A. R. 2020. The classification of upwelling indicators base on sea surface temperature, chlorophyll-a and upwelling index, the case study in Southern Java to Timor Waters. In IOP Conference Series: Earth and Environmental Science . 530 (1): :012020

Ratnawati, H. I., Hidayat, R., Bey, A., \& June, T. 2017. Upwelling di Laut Banda dan Pesisir Selatan Jawa serta hubungannya dengan ENSO dan IOD. Omni-Akuatika, 12(3).

Saji, N. H. et al,. 1999. A Dipole Mode in the Tropical Indian Ocean, Nature, 40(1) : 360-363.

Sartimbul, A., Nakata, H., Rohadi, E., Yusuf, B., \& Prasetyo, H. 2010. Progress in Oceanography Variations in Chlorophyll-a Concentration and the Impact on Sardinella lemuru catches in Bali Strait, Indonesia. Progress in Oceanography, 87(1-4), 168-174.

Sugiyono. 2009. Metode Kuantitatif, Kualitatif dan R\&D. Cetakan ke 8. Alfabeta, Bandung, hlm 53-60

Susanto, D., \& J. Marra. 2005. Effect of the 1997/1998 El Niño on Chlorophyll-a Variability along the Southern Coast of Java and Sumatera. Journal Oceanography, 18(4):124-127. 
Wirasatriya, A., J. D. Setiawan, D. N. Sugianto, I. A. Rosyadi, H. Haryadi, G. Winarso, R. Y. Setiawan, and R. D. Susanto. 2020. Ekman Dynamics Variability along the Southern Coast of Java Revealed by Satellite Data. International Journal of Remote Sensing 41 (21): 8475-8496.

Wyrtki K. 1961. Physical Oceaography of South East Asia Waters. Naga Report. Scripps Institution of Oceanography La Jolla California. The University of California.

Yamagata, T., Lizuka dan Matsura. 2000. Successful Reproduction of the Dipole Mode Phenomenon in the Indian Ocean Using a Model-Advance toward the Prediction of Climate Change. J. Geophys. Res. 27(20) : 3369-3372.

Yuliananingrum, T. L. P., \& Putri, M. R. 2012. Kondisi Oseanografi di Selat Sunda dan selatan Jawa Barat pada Monsun Barat 2012. PROSIDING, 49. 